\title{
Numerical and Experimental Study of a Continuous Electrostatic Smoking Process
}

\author{
Régis Baron, Michel Havet, Camille Solliec, Daniel Pierrat, and Gérard Touchard
}

\begin{abstract}
The smoking process is a batch one with long duration processing (some hours). Deposition of smoke particles can be enhanced by electrostatic precipitation. However, a better knowledge of the fundamental physics is needed to optimize the process. We carried out experimental and numerical studies to obtain essential information on the smoke flow. First, experiments physically characterized the wood smoke. These measures lead us to study the turbulent two-phase flow using an algebraic slip model. The main coupling with electrical forces is taken into account through the slip velocity. Various assumptions were tested concerning the coupled phenomena in order to build an algorithm that is able to simulate these phenomena. Numerical resolutions are compared with data from the literature on a simple electrostatic precipitator (three wires between two plates). Simultaneously, experiments were performed on a simplified scaled-down model of the smoking process (wires and one plate). The results of particle image velocimetry show clearly that the electrostatic precipitation phenomenon is effective above a threshold voltage and is significantly influenced by geometry of electrodes. Experiments and numerical resolutions underwent a validation phase. A small-size industrial demonstrator, of which the promising results will not be discussed in this paper, was conceived by exploiting the presented works.
\end{abstract}

Index Terms-Electrostatic precipitators, smoke particles, smoked salmon.

\section{INTRODUCTION}

$\mathbf{T}$ HE SMOKING process is one of the oldest known methods for preserving fish. After being slightly salted and dried, they are subjected to the action of smoke. Nowadays, the smoking process is particularly used for organoleptic goals. The fish smoking process consists in several steps: the heading, gutting, filleting, and trimming of the fish [1], followed by salting, drying, and smoking of the fillets. Smoking gives a characteristic flavor, due mainly to the phenolic compounds, a coloring of the products, a modification of texture, and a

Paper MSDAD-07-62, presented at the 2006 ESA/IEEE/IEJ/SFE Joint Conference on Electrostatics, Berkeley, CA, June 20-23, and approved for publication in the IEEE TRANSACTIONS ON INDUSTRY APPLICATIONS by the Electrostatic Processes Committee of the IEEE Industry Applications Society. Manuscript submitted for review June 30, 2006 and released for publication November 29, 2007. Published July 23, 2008 (projected).

R. Baron is with the IFREMER National Institute, 44311 Nantes Cedex 03, France (e-mail: rbaron@ ifremer.fr).

M. Havet is with UMR CNRS 6144 Génie des Procédés-EnvironnementAgroalimentaire, ENITIAA, 44322 Nantes Cedex 03, France.

C. Solliec is with UMR CNRS 6144 Génie des Procédés-EnvironnementAgroalimentaire, EMN, 44300 Nantes, France.

D. Pierrat is with CETIM, 44000 Nantes, France.

G. Touchard is with the Groupe d'Electrofluidodynamique, UMR CNRS 6609 Laboratoire d'Etudes Aérodynamiques, 86962 Futuroscope Cedex, France.

Color versions of one or more of the figures in this paper are available online at http://ieeexplore.ieee.org.

Digital Object Identifier 10.1109/TIA.2008.926239 longer shelf life [2]. Several factors determine the deposition and the diffusion of smoke such as density, temperature, and moisture of the smoke and moisture of the fillet surface, the air velocity around the product, and the duration of process. Smoke is generally produced by the incomplete combustion of sawdust or shavings, or from a friction generator. During smoking in an air-conditioning smoking kiln, the fillets are impregnated with smoke compounds while continuing to be dehydrated. The industrial process is still a batch one, and this traditional technique leads to long duration processing (some hours). One alternative approach to enhance the kinetics of deposition of particles of smoke is the electrostatic smoking process, which is kept in the more general scope of electrostatic precipitation. It is a continuous process which reduces the smoking operation to some minutes [3]. It consists in conveying fish in a tunnel through an electrostatic field. Fig. 1 shows a schema of this process associated with the simultaneous salting and drying phases (osmotic principles perform by a shower).

\section{Electrostatic Precipitation Overview}

The electrostatic smoking process of food is in keeping with the more general scope of electrostatic precipitation [4], [5]. Electric discharges form the basis of electrostatic precipitation because they generate the ions at the origin of the charge acquired by the particles [6]. Typically, an arrangement of successive wires is faced to a large electrode, generally a plate connected to the ground. At the vicinity of the discharge electrode, a nonuniform and very intense electric field is generated. The "corona discharge" is influenced by the polarity of the discharge electrode and by the gas properties. All the concerned phenomena are complex and, at the present time, only partially formalized [7]. Fig. 2 shows a sketch of the coupling effects between the particulate phase (smoke), the gas phase (air), and the electrical corona [4].

The transported particles (particulate phase) undergo the combined action of the electric forces and the turbulent flow of the carrying phase (gas phase). An electrohydrodynamic current produced by corona discharges (ionic wind) adds to the turbulent flow of the carrying phase. The particle trajectories depend on the gravity force, the viscous drag force of particles in the carrying phase, and a Coulomb force. In order to select the more convenient modeling approach of the electrostatic process, we needed to better characterize the smoke properties.

\section{Physical Characterization of SMoke Particles}

Wood smoke is composed of two phases, namely, a particulate (or dispersed) phase and a gaseous (or dispersing) 


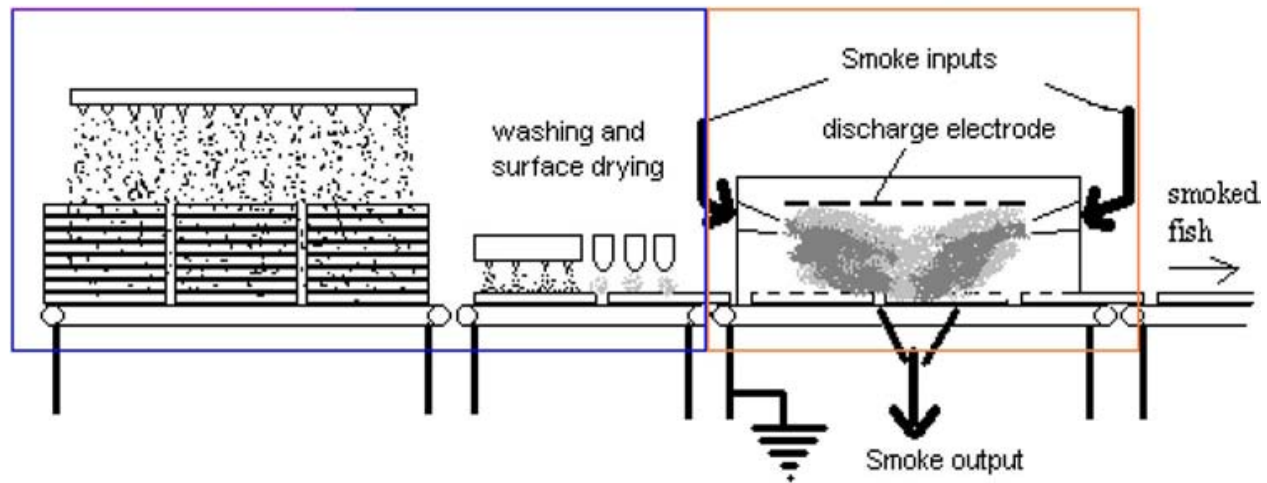

Fig. 1. Continuous salting-drying-smoking process.

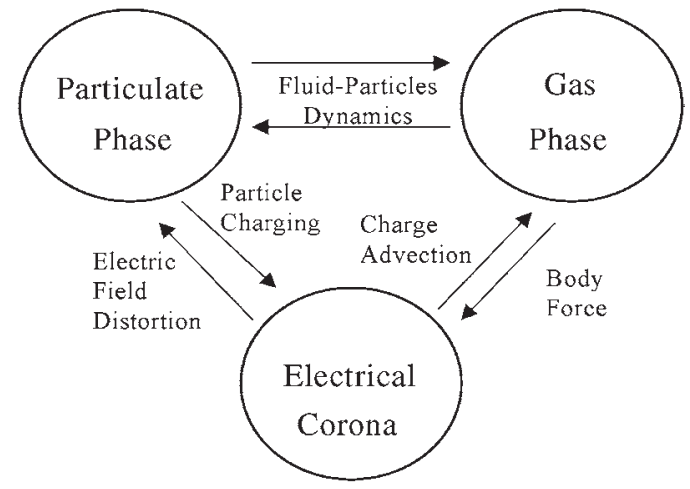

Fig. 2. Coupling between components of the model.

phase. The dispersed phase is the visible portion of smoke, and the particles are usually in the form of liquid droplets formed by condensation. The literature is neither abundant nor consensual on particle distribution. According to Maga [2], the particles from all smoke sources have an average diameter between 0.196 and $0.346 \mu \mathrm{m}$. For Kleeman et al. [8], particle distribution ranges between 0.02 and $0.250 \mu \mathrm{m}$. According to Sainclivier [9], in a "young" smoke produced by an autocombustion generator, droplets are very small (approximately $0.1 \mu \mathrm{m}$ ), but their size changes as a function of time. Droplets collide with one another due to Brownian motion and coalesce to form larger particles. From these considerations, it was necessary to carry out experiments in order to analyze the distribution of smoke particles emitted from a friction generator (MUVERO FOOD, model Technic FR1002). In this generator, an intact wood block is pressed against a rapidly rotating metal friction wheel. Friction causes wood pyrolysis to produce instantaneous and dense smoke. Particle size determination was run at least in duplicate using a Malvern Master Sizer S (Malvern Instruments, Ltd.) laser diffraction analyzer with a 300-mm Fourier cell. We assumed spherical particles and the median diameter $D[v, 0.5]$, the size at which $50 \%$ of particles by volume are smaller and $50 \%$ are larger was chosen to allow comparisons with literature data. The refractive indices of particles and gas phases were 1.45 and 1.00 , respectively.

Fig. 3 shows two experimental distributions obtained for a smoke having a lag time of $15 \mathrm{~min}$. This can be suitably

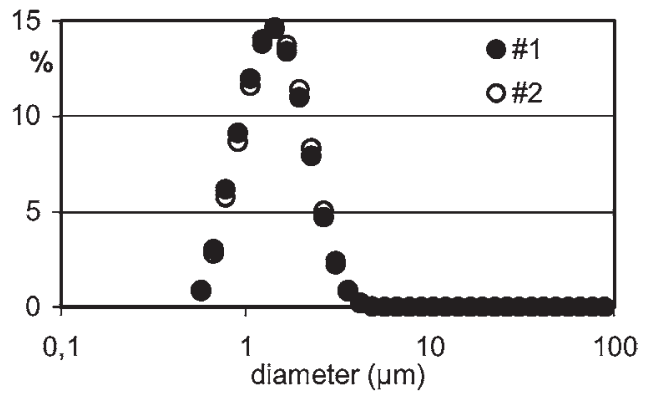

Fig. 3. Granulometric distribution of smoke of beech after $900 \mathrm{~s}$.

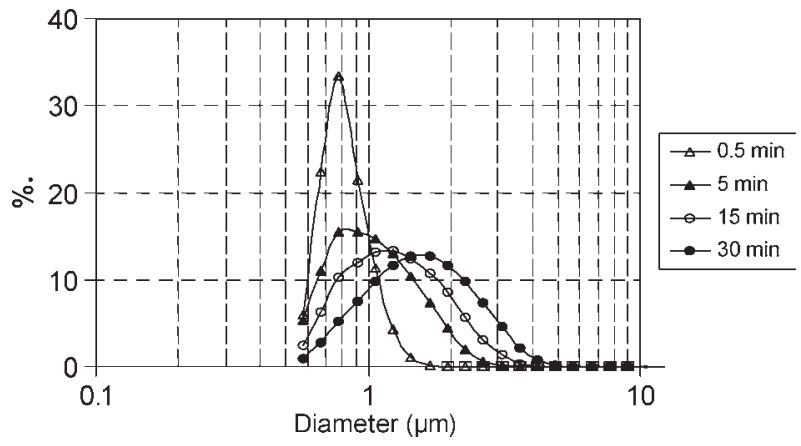

Fig. 4. Evolution of the granulometric distribution of smoke with time.

modeled by a log-normal distribution characterized by a median diameter that is equal to $1.31 \mu \mathrm{m}$. This value is greater than those of the literature. It is mainly due to coagulation effects: the lag time in the box plug. Our experiments showed an increase of the median diameter and of the span with time (Fig. 4).

The increase of the median diameter can be modeled according to the coagulation by Brownian diffusion for a monodisperse distribution [10]

$$
d_{p}(t)=d_{p 0}\left(1+N_{0} K t\right)^{3}, \quad N(t)=\frac{N_{0}}{1+N_{0} K t}
$$

where $d_{p}$ is the diameter, $d_{p 0}$ is the initial diameter, $N_{0}$ is the initial numeric particle concentration, and $K$ is the coagulation coefficient.

Adjustment of the various coefficients provided the following values: $d_{p 0}=0.60 \mu \mathrm{m}, K=3.57 \cdot 10^{-16}$, and $N_{0}=1.4 \cdot 10^{13}$ particles $/ \mathrm{m}^{3}$. As the coagulation phenomenon 
is well predicted, it permits deducing the initial diameter and concentration of particles.

From these results, the volume fraction of smoke particles was calculated $\left(1.6 \cdot 10^{-6} \mathrm{~m}^{3} / \mathrm{m}^{3}\right)$ and found to be very dilute.

\section{Physical Modeling of Flow}

The particulate two-phase flow is described basically in two ways, namely, the Lagragian and the Eulerian methods. The Lagrangian technique permits following each particle by calculation of all trajectories using balance equations. It presents some drawbacks because a great number of trajectories should be calculated and it requires very short time steps and great computational resources. The Eulerian technique considers two phases with an interface and requires the calculation of momentum equations for each phase.

By considering the results of the experimental characterization, i.e., the smoke is dilute and the relaxation time of particles is low, choose an alternative modeling approach: the algebraic slip model (ASM).

We consider a mixture which is a continuous medium in which there is a dispersed phase, like described by Ishii [11] or in Manninen et al. [12]. In this approach, the continuous and dispersed phases behave as a single fluid of velocity $u^{m}(1)$. It is valid for particles having a diameter less than $5 \mu \mathrm{m}$. A classical Reynolds Average Navier-Stokes equation is used to model the turbulence, and the ionic wind is considered as a source term in the momentum equation of the continuous phase (2). For the particle phase of smoke, we consider a transport equation for each $p$ class of particle with a volume fraction $r_{p}$ (3). The slip velocity $u^{p}$ (relative to the mixture velocity $u^{m}$ ) depends on the electric charge of the particles $q_{p}$, the electric field $E$ and the particle diameter $d_{p}$ (4). A Poisson equation permits one to calculate the electric potential by taking into account the ionic charge and the particle charge density (5). $V_{p}$ is the mean volume of particle of size class

$$
\begin{aligned}
& \frac{\partial \rho_{c}}{\partial t}+\frac{\partial \rho_{c} u_{i}^{m}}{\partial x_{i}}=0 \\
& \frac{\partial \rho_{c} u_{i}^{m}}{\partial t}+\frac{\partial}{\partial x_{i}}\left(\rho_{c} u_{i}^{m} u_{j}^{m}-\mu_{c}\left(\frac{\partial u_{j}^{m}}{\partial x_{i}}+\frac{\partial u_{i}^{m}}{\partial x_{j}}\right)\right) \\
& \quad=\frac{\partial P}{\partial x_{i}}+\rho_{\text {ion }} E_{i}
\end{aligned}
$$

$\forall p=1, \ldots, j ; \frac{\partial \rho_{p} r_{p}}{\partial t}+\frac{\partial}{\partial x_{i}}\left(\rho_{p} r_{p}\left(u_{i}^{m}+\left(u_{g}^{p^{\prime}}\right)_{i}\right)=D_{e}\left(x_{i}\right)\right.$

$$
\left(u_{g}^{p^{\prime}}\right)_{i}=\frac{q_{p} E_{i}}{3 \pi \mu d_{p}}
$$

$\Delta \phi=\frac{\rho_{\text {ion }}+\sum_{p=1, \ldots, j} N_{p} q_{p}}{\varepsilon 0}$

$N_{p}=\frac{r_{p}}{V_{p}}$

$E=-\nabla \phi$

$$
\begin{aligned}
& \frac{\partial \rho_{\text {ion }}}{\partial t}+\frac{\partial}{\partial x_{i}}\left(\rho_{\text {ion }}\left(b_{\text {ion }} E_{i}+u_{i}^{m}\right)-D_{\text {ion }} \frac{\partial \rho_{\text {ion }}}{\partial x_{i}}\right) \\
& =-\sum_{N=1}^{p} N_{p} \frac{d q_{p}}{d t} \\
& \forall p=1, \ldots, j ; \frac{\partial N_{p} q_{p}}{\partial t}+\frac{\partial}{\partial x_{i}}\left(\left(u_{i}^{m}+\left(u_{g}^{p^{\prime}}\right)_{i}\right) N_{p} q_{p}\right) \\
& =N_{p} \frac{d q_{p}}{d t} \\
& \frac{d q_{p}}{d t}=\frac{\rho_{\text {ion }} b_{\text {ion }}}{4 \varepsilon_{0} q_{p}^{\max }}\left(q_{p}^{\max }-q_{p}\right)^{2} \\
& q_{p}^{\max }=p_{\varepsilon} \pi \varepsilon_{0}\|E\| d_{p}^{2} \\
& P_{\varepsilon}=1+2 \frac{\left(\varepsilon_{r}-1\right)}{\left(\varepsilon_{r}+2\right)}
\end{aligned}
$$

$D_{e}\left(x_{i}\right)$ is a deposition function around the product to treat. $\rho_{c}$ and $\rho_{\text {ion }}$ are the mass density of the continuous phase and the ion charge density. Turbulent viscosity $\mu_{c}$ can be calculated from the conservation equations of turbulence kinetic energy and turbulence dissipation rate in the RNG $\mathrm{k}-\varepsilon$ model for example [13]. Ions generated by the electric breakdown adhere to the particles suspended in the gas stream and charge them. The charging rate of assumed spherical particle by the field charging mechanism is given by Cross expression [14] with $q^{\max }$ as the maximum possible charge by the local electric field at the particle's location (11). $\varepsilon_{r}$ and $\varepsilon_{0}$ are permittivity of free space and relative permittivity of the gas [see (10) and (12)].

The distribution of ion charge density is given with respect to the current continuity equations [see (8) and (9)] with $b_{\text {ion }}$ as the mobility of ions and $D_{\text {ion }}$ as the effective diffusivity of ions.

Concentrated particle space charge near wires works to reduce the strength of the electric field and the corona current from the discharge electrode. Spatially different particle concentration results in a different electric current at each wire. The strengths of the electric field at the surface of all wire electrodes satisfy Peek's formula [15]. Ion charge density at each wire is adjusted by the special convergent procedure to obtain the local electric field in agreement with the value calculated from Peek's formula.

\section{NUMERICAL SOLUTIONS AND COMPARISONS WiTH LITERATURE RESULTS}

The CFD Code CFX4.4 (AEA Technology) was customized in order to solve these fully coupled equations in a 2-D case. Our model was firstly tested on the configuration previously studied by Choi and Fletcher [4]: an electrostatic precipitator with three wires and two collecting plates (Fig. 5).

Whereas we consider the whole domain, Choi and Fletcher worked on a half one for symmetry reasons. Figs. 6 and 7 show their results concerning the mean particle trajectories and the particle mass concentration. It appears that the particles that have a mean diameter of $2 \mu \mathrm{m}$ are deviated just upstream the first wire toward the collecting plate. Our results (Fig. 8) presented on the whole domain are also in a very good 


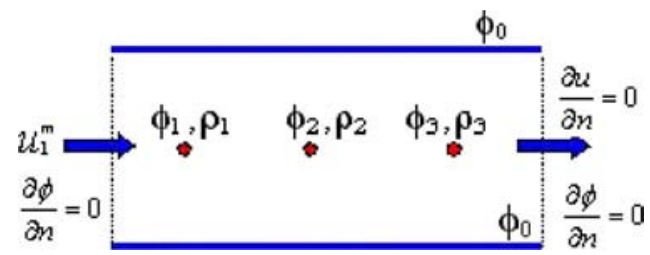

Fig. 5. Configuration of Choi and Fletcher [2], geometry, and boundary conditions.

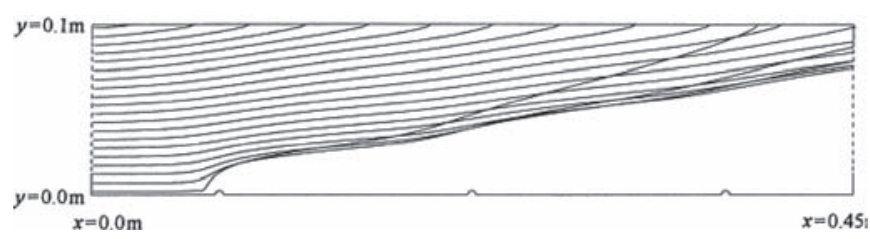

Fig. 6. Electrostatic precipitator: mean particle trajectories for $d_{p}=$ $2 \mu \mathrm{m}$ [4].

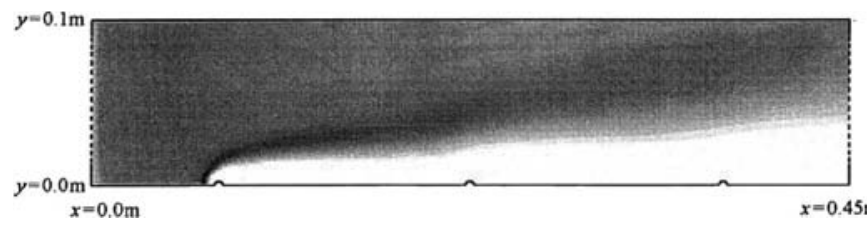

Fig. 7. Electrostatic precipitator: particle mass concentration for $d_{p}=$ $2 \mu \mathrm{m}$ [4].

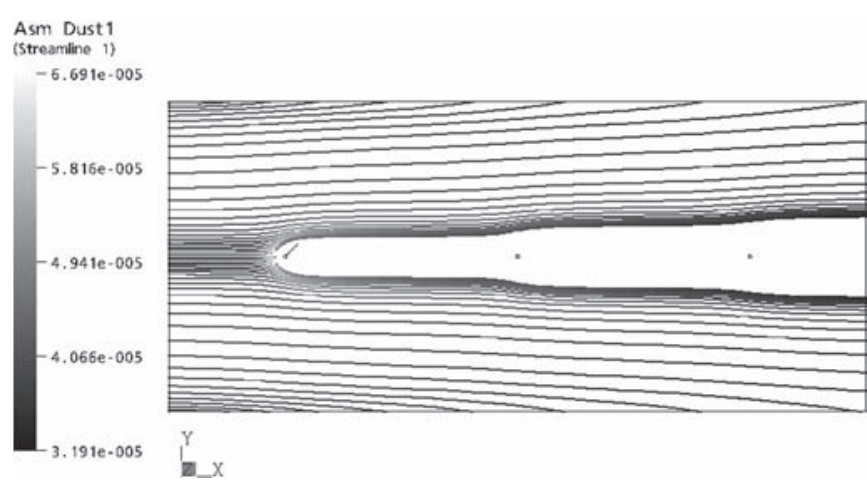

Fig. 8. Electrostatic precipitator: simulations of particle concentration and trajectories with our model in the same conditions for $d_{p}=2 \mu \mathrm{m}$.

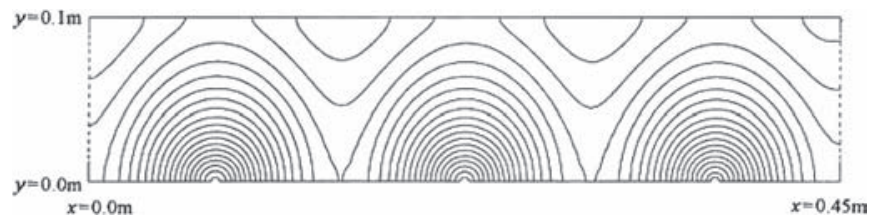

Fig. 9. Electrostatic precipitator: ion charge density distribution for $\left(\rho_{\mathrm{pc}}\right)_{\text {in }}=0 \mathrm{~g} / \mathrm{m}^{3}$ and $\left(\rho_{\text {ion }}\right.$ at wires $)=45.7 \mu \mathrm{C} / \mathrm{m}^{3}[4]$.

qualitative and quantitative correspondence with those of Choi and Fletcher. It should be noticed that for particles having a greater mean diameter (up to $5 \mu \mathrm{m}$ ), the trajectories are different and they are more quickly collected. We also compared our results concerning the distribution of the ion charge density for a value fixed at $45.7 \mu \mathrm{C} / \mathrm{m}^{3}$ on the wires. We can observe a very good agreement between both simulations (Figs. 9 and 10).

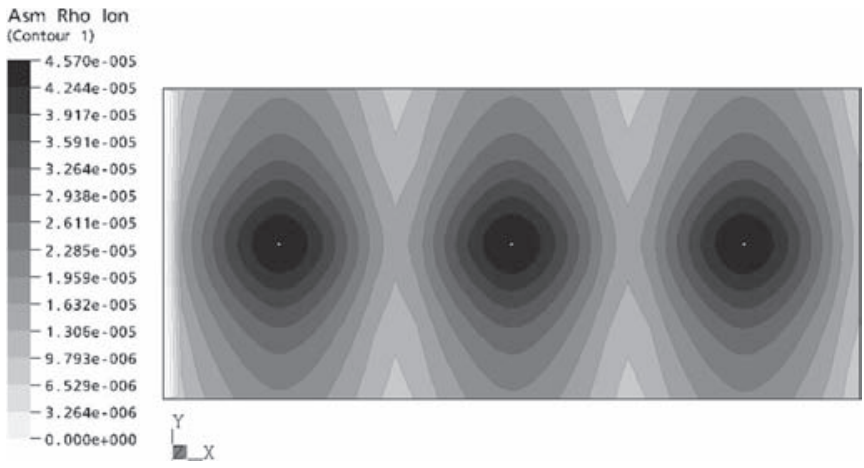

Fig. 10. Electrostatic precipitator: simulations of ion charge density with our model in the same conditions.

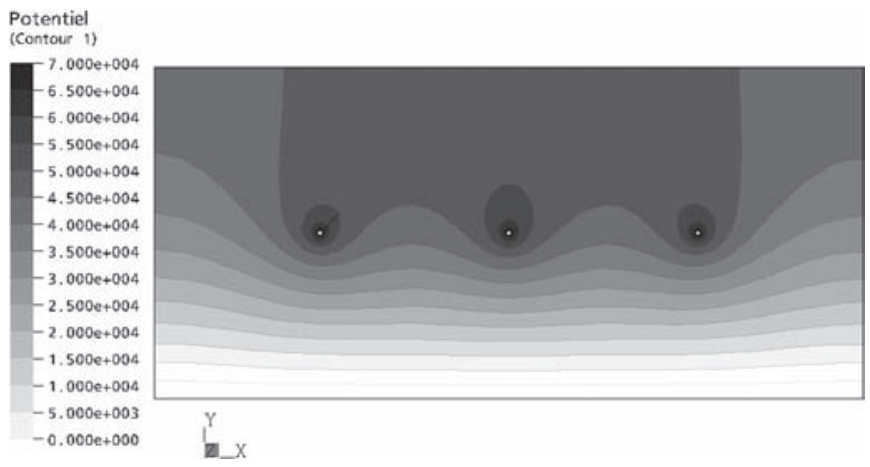

Fig. 11. Electrostatic smoking process: voltage distribution with $40 \mathrm{kV}$ at wires and $0 \mathrm{kV}$ on down plate.

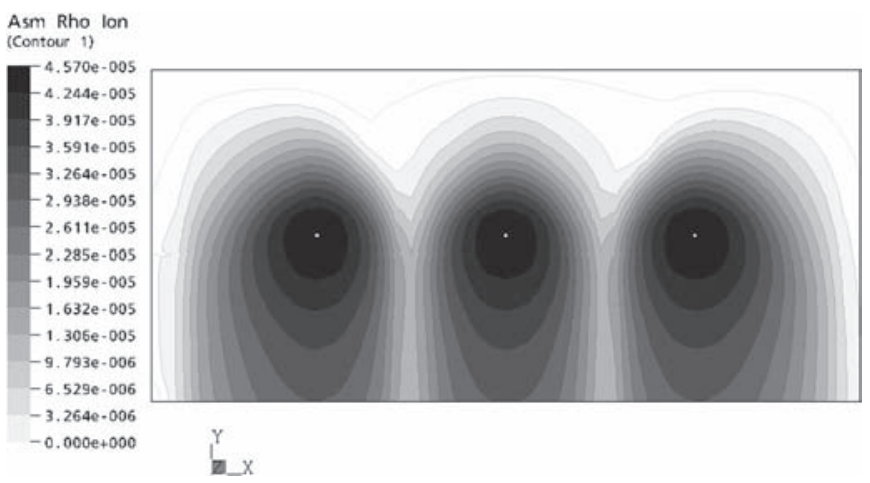

Fig. 12. Electrostatic smoking process: ion charge density distribution for $\left(\rho_{\mathrm{pc}}\right)_{\text {in }}=0 \mathrm{~g} / \mathrm{m}^{3}$ and $\left(\rho_{\text {ion }}\right.$ at wires $)=45.7 \mu \mathrm{C} / \mathrm{m}^{3}$.

This preliminary study confirmed that our model and algorithm are efficient to predict the electrostatic precipitation and flow of small particles. Moreover, as our approach does not require great computational times, it permits one to treat the whole domain and then to investigate other geometries that do not present symmetry conditions. This is typically the case of the smoking tunnel.

We consider, for our simulations of the smoking process, three wires at $40 \mathrm{kV}$, a grounded collecting plate $(y=0)$, and an insulated one $((\partial \phi / \partial n)=0$ at $y=0.2 \mathrm{~m})$. The inlet velocity is fixed at $1 \mathrm{~m} / \mathrm{s}$. The voltage (Fig. 11) and ion charge density (Fig. 12) distributions confirm that there is no more symmetry along the centerline. The particle entering below this centerline would be collected, whereas the other would not be. 

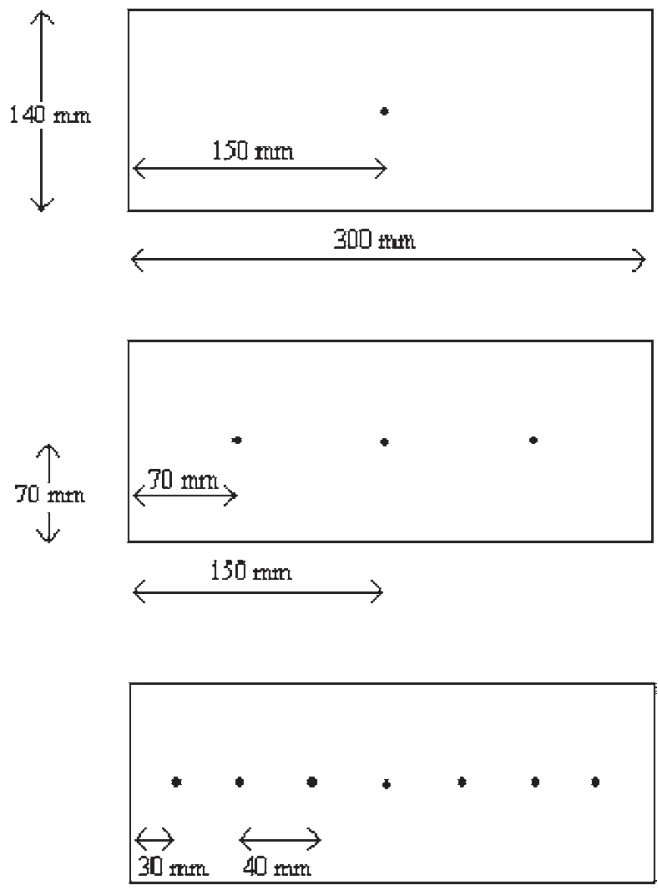

Fig. 13. Corona wire positions in the tunnel.

\section{EXPERIMENTAL Visualization of PaRTicle Flow AND COMPARISONS WiTH SiMULATION RESULTS}

Simultaneously, experiments were performed on a simplified scaled-down model of the smoking process (one or multiple wires and one grounded plate). Various arrangements were investigated, allowing different electrostatic fields imposed within the test enclosure. Depending on cases, aerodynamic and electrostatic forces combine their effects rather differently to produce the smoke deposition. The experimental apparatus (Fig. 13) consists in a smoking tunnel $(300 \mathrm{~mm} \times 140 \mathrm{~mm})$ made of plexiglas to allow flow visualizations and particle image velocimetry (PIV) measurements. The inlet flow velocity can be set to any desired value between 0.15 and $3 \mathrm{~m} \cdot \mathrm{s}^{-1}$. A settling chamber located upstream the smoking tunnel ensures smoke homogeneization before injection in the tunnel. Fresh air can be provided and mixed with the smoke for dilution, if necessary. Measurements were carried out by PIV (for various geometrical arrangements of the ionization electrode. The CCD camera $(1008 \times 1016$ pixels $)$ was attached to a micrometric traversing system allowing accurate focusing with respect to the laser light sheet. Pairs of images were recorded at a frequency of $15 \mathrm{~Hz}$. Data were acquired during about $30 \mathrm{~s}$ in almost all cases so as to ensure statistically accurate time-averaged velocity fields. Three configurations were investigated: one, three, or seven corona wires (diameter $=2 \mathrm{~mm}$ ) stretched spanwise across the median plane of the smoking chamber (Fig. 13). The electrical voltage applied to the wires was varied between 0 and $\pm 40 \mathrm{kV}$. The first test series was conducted with no voltage at wire $\left(\phi_{w}=0 \mathrm{kV}=\right.$ voltage at wire) to assess the aerodynamic performance of the test bench and to find appropriate data analysis parameters The mean velocity field was found uniform and homogeneous, as was expected in this case (Fig. 14).

Fig. 15 shows an instantaneous image for the single-wire case at $40 \mathrm{kV}$. The vertical line is due to the shadow of the

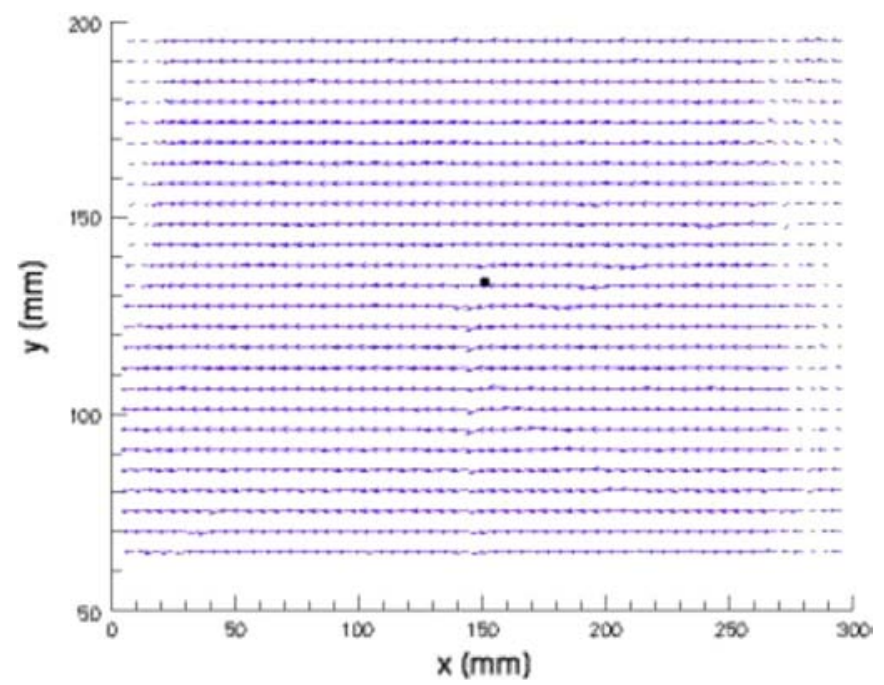

Fig. 14. Velocity field in the tunnel when no potential is applied on the wire.

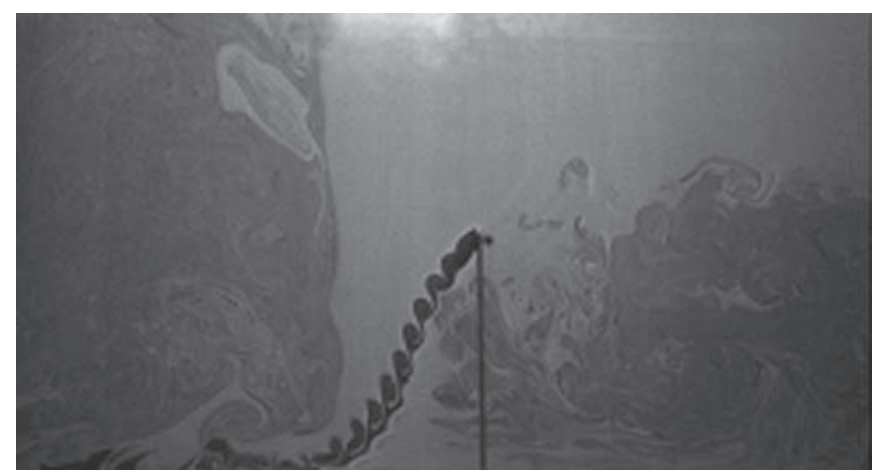

Fig. 15. Instantaneous picture for the single-wire cases, $\phi_{w}=40 \mathrm{kV}$.

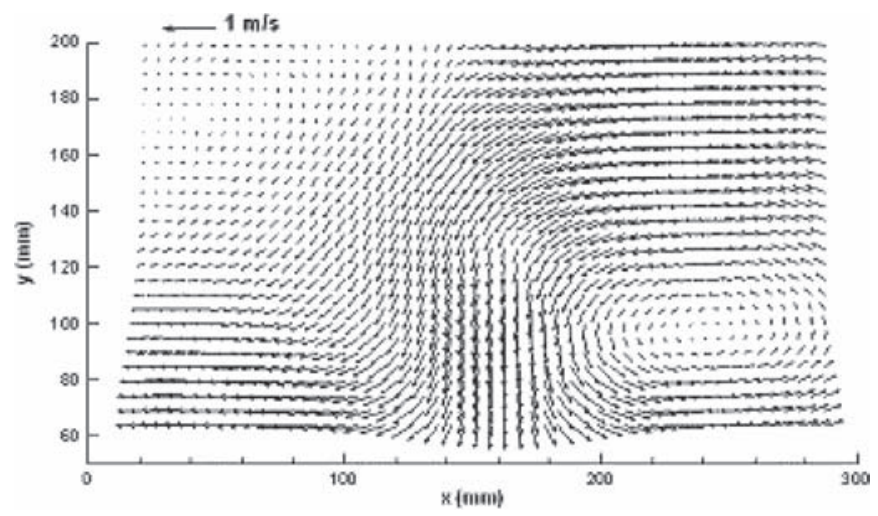

Fig. 16. Particle mean vector velocity field (one wire, $\phi_{w}=40 \mathrm{kV}$ ).

wire. This figure reveals the complex flow downstream the wire. The mean velocity obtained by PIV in this case indicates that particles go toward the collecting plate and generate a recirculation zone upstream the wire (Fig. 16).

Figs. 17 and 18 show instantaneous images for three and seven wires at $40 \mathrm{kV}$, respectively. They confirm the very complex flow resulting from the combination of the main flow and the flow generated by multiple wires. The smoke particle mean vector velocity field is shown in Figs. 19 and 20 for these 


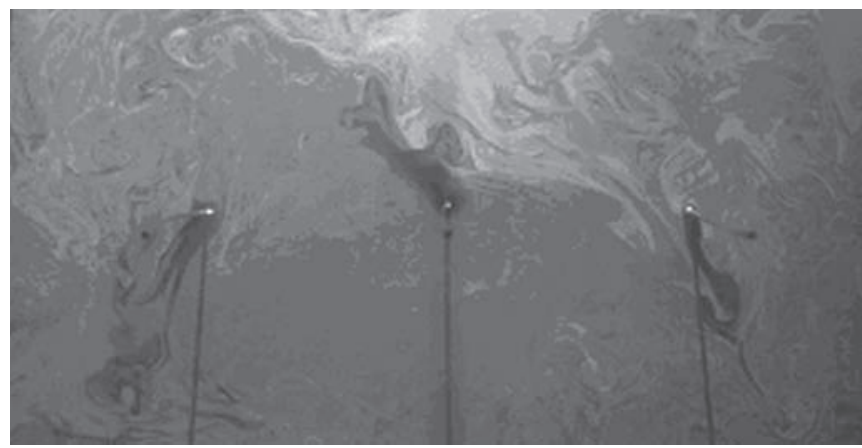

Fig. 17. Instantaneous picture for the triple-wire cases, $\phi_{w}=40 \mathrm{kV}$.

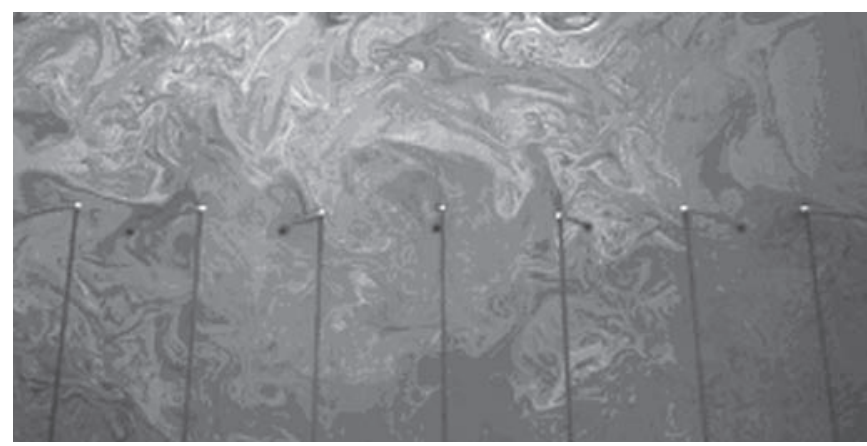

Fig. 18. Instantaneous picture for the seven-wire cases, $\phi_{w}=40 \mathrm{kV}$.

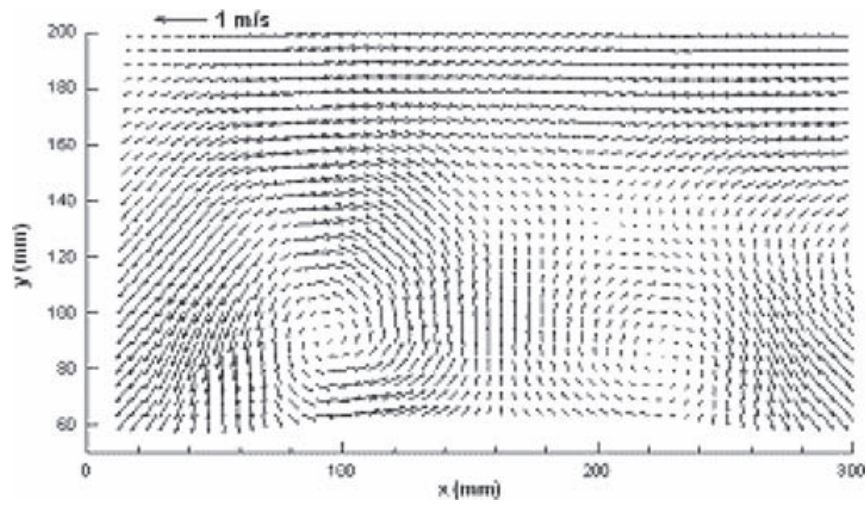

Fig. 19. Particle mean vector velocity field (three wires, $\phi_{w}=40 \mathrm{kV}$ ).

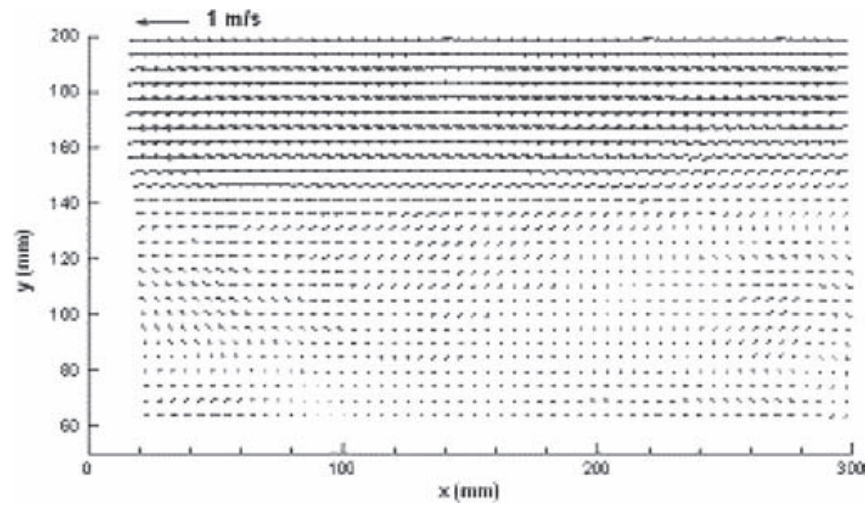

Fig. 20. Particle vector velocity field (seven wires, $\phi_{w}=40 \mathrm{kV}$ ).

cases. It could be noticed for this latter configuration that a great part of the trajectories are linear and that the particles above the wires are not directed toward the grounded plate.

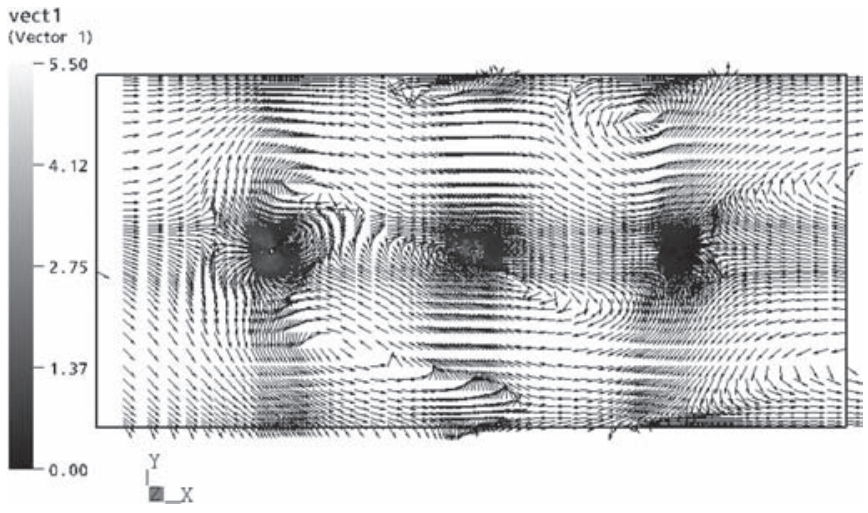

Fig. 21. Simulation with the same conditions as the experiment in Fig. 19.

Experiments indicate that the electrical potential, the number of wires, and the distance between wires are decisive parameters in designing electrostatically enhanced smoking processes. Wires too closely separated tend to result in a global breaking of electrostatic field effects and lead to a reduced smoke precipitation. It is likely that a minimum distance under which field effects may cancel each other should be respected between wires. In the case of multiple wires, the flow could be rather complex as illustrated by the simulation results (Fig. 21).

If a qualitative comparison is possible with experimental measurements, quantitative differences are still observed. The mathematical modeling and simulation tools could be beneficial for the optimization of process demonstrator design. Our model would be improved by an iterative process that would permit one to calculate the ion charge density at the wires instead of imposing a fixed value. We also carried out experiments in an industrial demonstrator more focused on biochemical and sensorial aspects applied to Atlantic salmons. Results, not presented in this paper, clearly showed the potential of this new process.

\section{CONCLUSION}

The electrostatic smoking process is a promising technology which should be investigated before implementation by the fish industry. This paper has provided a better understanding of the physical phenomena and smoke characteristics. We have shown that the median diameter of smoke particles is close to $0.7 \mu \mathrm{m}$ and that coagulation effects appear. These experimental results lead us to choose the ASM model to numerically predict the flow of smoke under electrostatic conditions. The electrohydrodynamic model was solved to predict the physical phenomena encountered in an electrostatic precipitator. The results are useful, but further investigations should be carried out in order to improve the model and its resolution to validate it using more experimental data.

\section{REFERENCES}

[1] C. Knockaert, "Le fumage du poisson," in Service de la documentation et des publications. Brest, France: Ifremer, 1990.

[2] J. Maga, Smoke in Food Processing. Boca Raton, FL: CRC Press, 1988.

[3] A. Collignan, C. Knockaert, A. L. Raoult-Wack, and J. L. Vallet, "Procédé et dispositif de salage, séchage et de fumage à froid de produits alimentaires carnés," French Patent Ifremer/Cirad 92/08 958, 1992. 
[4] B. S. Choï and C. A. J. Fletcher, "Turbulent particle dispersion in an electrostatic precipitator," Appl. Math. Model., vol. 22, no. 12, pp. 10091021, Dec. 1998.

[5] S. J. Park and S. S. Kim, "Effects of particle space-charge and turbulent diffusion on performance of plate-plate electrostatic precipitators," J. Electrostat., vol. 45, no. 2, pp. 121-137, Dec. 1998.

[6] J. Chen and J. H. Davidson, "Electron density and energy distributions in the positive DC corona: Interpretation for corona-enhanced chemical reactions," Plasma Chem. Plasma Process., vol. 22, no. 2, pp. 199-222, Jun. 2002.

[7] P. Tochon, "Etude numérique et expérimentale d'électrofiltres industriels," Ph.D. dissertation, Université Joseph Fourier, Grenoble I, Grenoble, France, 1997.

[8] M. J. Kleeman, J. J. Schauer, and G. R. Cass, "Size and composition distribution of fine particulate matter emitted from wood burning, meat charbroiling, and cigarettes," Environ. Sci. Technol., vol. 33, no. 22, pp. 3516-3523, 1999.

[9] M. Sainclivier, "L'industrie alimentaire halieutique. Chapitre V: Le fumage," Bulletin scientifique et technique de l'école nationale supérieure agronomique et du centre de recherches de Rennes, 1985.

[10] W. Hinds, Aerosol Technology_Properties, Behavior and Measurement of Airbone Particles. Hoboken, NJ: Wiley, 1999.

[11] M. Ishii, Thermo-fluid Dynamic Theory of Two-Phase Flow. Paris, France: Eyrolles, 1975.

[12] M. Manninen, V. Taivassalo, and S. Kallio, On the Mixture Model for Multiphase Flow. Espoo, Finland: VTT Publications 288, 1996.

[13] O. Rouaud and M. Havet, "Computation of the air flow in a pilot scale clean room using $\mathrm{K}-\varepsilon$ turbulence models," Int. J. Refrigeration, vol. 25, pp. 351-361, 2002.

[14] J. Cross, Electrostatics: Principles Problems and Application. Bristol, U.K.: Adam Hilger, 1987.

[15] F. W. Peek, Dielectric Phenomena in High Voltage Engineering. New York: McGraw-Hill, 1929.

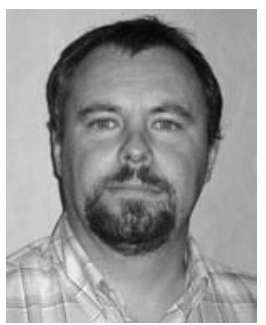

Régis Baron was born in Brittany, France, in 1968. $\mathrm{He}$ received the Ph.D. degree in physics, with specialization in signal processing and control, from the University of Paris-Sud 11, Orsay, France, in 1995.

Since then, he has been with the Seafood Science and Technology Department, National Institute on Marine Research (IFREMER). His work concerns the dynamic modeling of marine biological resources conversion processes for their design and control.

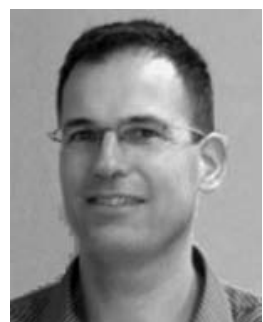

Michel Havet was born in Brittany, France, in 1968. $\mathrm{He}$ received the Ph.D. degree in fluid mechanics and thermal engineering from the University of Poitiers, Poitiers, France, in 1995.

Since 1996, he has been with the Ecole Nationale d'Ingénieurs des Techniques des Industries Agricoles et Alimentaires (ENITIAA), Nantes, France, a public institute of higher education and research affiliated with the French Ministry of Agriculture, where he is currently the Head of the Food Process Engineering Department. Since 2002, he has been carrying out his research in the GEPEA laboratory (Process Engineering for Environment and Food), a joint research unit of the CNRS (UMR CNRS 6144). His main research interests include enhancement of heat and mass transfer in convective food processes.

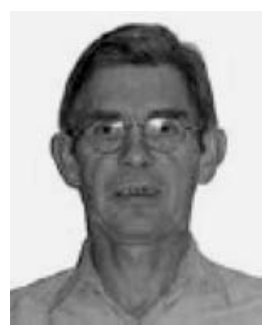

Camille Solliec was born in Brittany, France, in 1957. He received the degree in chemical engineering and energetic, hydrodynamic, and offshore engineering and the Ph.D. degree, with a specialization in fluid mechanics and heat transfer, from the Central School of Nantes, Nantes, France.

Between 1986 and 1993, he was a Research Engineer with the Scientific and Technical Center for Buildings. Since 1993, he has been an Associate Professor with the Mines School of Nantes, where he is currently a Professor. He is a member of the GEPEA CNRS Laboratory. Since its creation, he has been managing his research and teaching activities in this laboratory and in the Mines School of Nantes in most of his initial formation fields.

Daniel Pierrat is with the Technical Center of Mechanical Engineering Industries, Nantes, France, working on computational fluid dynamic codes.

\section{Gérard Touchard was born in 1944.}

He co-steers the "Electrohydrodynamic" team of the Aerodynamic Laboratory of Poitiers, Poitiers, France, a CNRS-associated unit for research. 